\title{
СЕРДЕЧНО-СОСУДИСТЫЕ ОСОБЕННОСТИ ТЕЧЕНИЯ САХАРНОГО ДИАБЕТА 2 ТИПА У МУЖЧИН С АНДРОГЕННЫМ ДЕФИЦИТОМ
}

\author{
Касимова А.М., Скуридина Д.В., Демидова Т.Ю. \\ ФГАОУ ВО РНИМУ им. Н.И. Пирогова, Москва
}

\begin{abstract}
АКТУАЛЬНОСТЬ: андрогенный дефицит является важным патогенетическим элементом развития метаболического синдрома и сердечно-сосудистых заболеваний у мужчин. При этом связь между сахарным диабетом, снижением уровня тестостерона и сосудистыми факторами риска является двунаправленной, т. е. эти группы нарушений взаимно усугубляют друг друга.

ЦЕЛЬ: изучить сердечно-сосудистые особенности течения сахарного диабета 2 типа (СД2) у мужчин с андрогенным дефицитом.
\end{abstract}

\section{ЗАДАЧИ ИССЛЕДОВАНИЯ.}

1. Оценить частоту встречаемости гипогонадизма у мужчин 35-65 лет с СД2.

2. Сравнить частоту нефатальных инфарктов миокарда и инсультов в анамнезе в группе пациентов с СД2 и гипогонадизмом с группой пациентов с СД2 без гипогонадизма.

МАТЕРИАЛЫ И МЕТОДЫ: в Исследование включено 124 мужчины с СД 2 типа. Для диагностики гипогонадизма проведено измерение уровней общего тестостерона (T), глобулина, связывающего половые гормоны (ГСПГ), альбумина и лютеинизирующего гормона (ЛГ). Расчет уровня свободного тестостерона (св.T) производился с помощью калькулятора Ghent University Hospital, Бельгия. У 43 пациентов проведен ретроспективный анализ историй болезни (наличие перенесенных инфарктов и инсультов, лабораторные данные - общий холестерин (XС), триглицериды (ТГ), глюкоза плазмы крови натощак, гликированный гемоглобин ( $\left.\mathrm{HbA}_{1 c}\right)$ ). Полученные данные обрабатывались в программе STATISTICA 12.

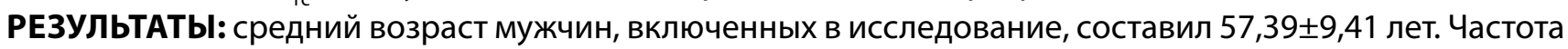
встречаемости лабораторно подтвержденного гипогонадизма ( $<<8,0$ нмоль/л и/или $\mathrm{T}<12,1$ нмоль/л+св. $\mathrm{T}<0,243$ нмоль/л) - 50,81\%. Выявлена средняя положительная корреляция между андрогенным дефицитом и частотой нефатальных сердечно-сосудистых событий ( $r=0,45 \mathrm{p}<0,05)$. При этом показатели углеводного и липидного обмена существенно не отличались между пациентами с гипогонадизмом и без $(p>0,05)$.

Выводы: выявленная частота гипогонадизма у мужчин с СД2 соответствует данным международных исследований. Наличие достоверной корреляции между низким уровнем тестостерона и сердечно-сосудистыми событиями у пациентов с СД2, позволяет предположить, что гипогонадизм может быть использован в качестве дополнительного критерия сердечно-сосудистого риска. 